speciation in the Hawaiian Islands (Templeton), and speciation of hummingbird flower mites, elsewhere described as stowaways on the hummingbird express (Colwell).

The two last sections on Population Genetics include papers on Mitochondrial DNA, Habitat preference in Drosophila, Suez canal migrationwhich way, what kind of species and why?, Evolutionary genetics of HLA, Gaussian versus non-Gaussian analyses of polygenic mutation-selection balance (an illuminating discussion by Michael Turelli), The Gaussian approximation for random genetic drift, W. D. Hamilton on Instability and cycling of two competing hosts with two parasites (I found this as obscure as much modern music), some more mathematics of altruistic behaviour, a mathematical model for the evolution of learning, and genetic models of endosperm evolution in higher plants.

I have failed to mention several possibly important articles, but potential readers with an interest in the more mathematical aspects of evolutionary studies and speculation may be encouraged by my listing of titles to examine the book or buy it in paperback. I cannot say that it should be purchased by all Genetics Department libraries, but at least the (comparatively) cheap paperback edition makes it available for those with a strong interest in many of the topics listed. No doubt articles in this compendium will soon get into the references in future papers, but most of what is included can be extracted from other publications, with a little patience.

ER IC REEVE Department of Genetics University of Edinburgh

\section{Practical Developments in Inherited Metabolic Disease: DNA Analysis, Phenylketonuria and Screening for Congenital Adrenal Hypoplasia. Edited by G. M. AdDison, R. A. Harkness, D. M. Isherwood and R. J. Pollitt. MTP Press Limited. 1986. 335 pages. f50.00. ISBN $085200690 \mathrm{X}$.}

This oddly titled book is, as the contents page makes clear, the proceedings of the 23rd Annual Symposium of the Society for the Study of Inborn Errors of Metabolism (SSIEM), held in September 1985. The assembled papers have already been published as two supplements to the Journal of Inherited Metabolic Disease. Membership of SSIEM includes subscription to the Journal and all its supplements and costs $£ 25.00$ per year. The above book costs $£ 50.00$. For those who are interested, there are obvious financial advantages in applying for membership of SSIEM.

Until quite recently, meetings of this Society have tended to concentrate on the detailed enzymology of those genetic disorders whose rarity allows the investigators to outnumber the patients. No aspect of seramidase deficiency, Zellweger's syndrome or short-chain fatty-acid oxidation defect was considered unworthy of minute examination and loving reporting. The standard of work has been high and the Journal is superbly edited and produced. However, much as one admires the dedication of those who engage in this type of very necessary investigation, their reports can be awfully dull reading for the interested onlooker.

The proceedings in this book represent the Society's attempts to come to terms with the 'new genetics'. A symposium on recombinant DNA includes some useful contributions from Sue Malcolm and Marcus Pembrey on principles of gene probing, chapters on phenylketonuria and $\alpha_{1}$-antitrypsin deficiency by Savio Woo, ornithine-transcarbamylase deficiency by Lee Rosenberg, and an interesting short account of the role of homologous recombination in gene insertion by Oliver Smithies. However, these chapters are already substantially out of date and the interested reader will have to check Nature or Proceedings of the National Academy of Sciences to see where the subject is now. Apart from the recombinant DNA section, which takes up the first third of the book, the remaining papers are detailed descriptions of the enzymology of the rare and the vanishing rare.

I welcome the attempt by SSIEM to put a tentative foot into the cold water of molecular biology. It must seem an alien world to many of its members. But one thing is clear: if the Society continues with its interest in DNA, it will have to stop publishing the proceedings of its annual meetings in hardback form. There was little enough justification for this in the past, given the availability of the same material in supplements of the Journal of Inherited Metabolic Disease. With the accelerating pace of progress in molecular biology, hardback proceedings are hopelessly dated by the time they appear. I could not, therefore, recommend this book to either individual readers or science libraries.

D. J. H. BROCK

Human Genetics

Western General Hospital

Edinburgh EH4 $2 X U$

Fourteenth Symposium on Nucleic Acids Chemistry. Held in Tokushima, Japan. 30 October to 1 November 1986. Nucleic Acids Symposium Series No. 17, IRL Press Ltd. Oxford. 272 pages. £27, \$49. ISBN 1852210036.

This is a special symposium edition of the journal Nucleic Acids Research. It is principally of interest to research workers in the areas of biological and pharmaceutical chemistry. The volume contains a great deal of innovative science but is generally short of experimental detail. I feel sure that any important work appearing here will have already surfaced or will shortly be seen in other scientific journals. A quick scan reveals some interesting statistics. Of the 235 contributors, 230 are Japanese, 4 American and 1 Belgian. This is not, then, an international symposium. On the positive side the 60 scientific papers on nucleic 